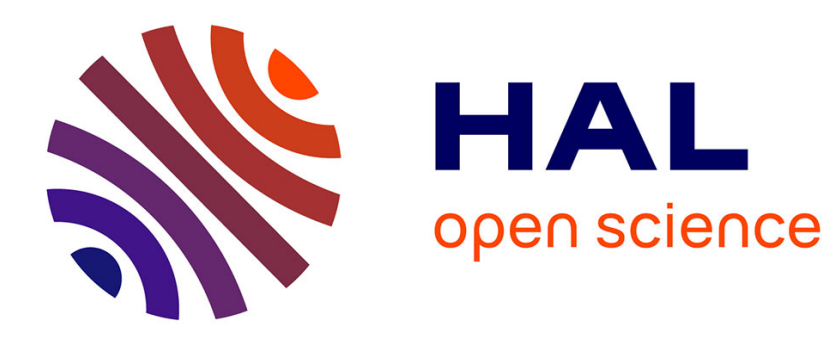

\title{
On discrimination in health insurance
}

Thomas Boyer-Kassem, Sébastien Duchêne

\section{To cite this version:}

Thomas Boyer-Kassem, Sébastien Duchêne. On discrimination in health insurance. Social Choice and Welfare, 2020, 55, pp.5-23. 10.1007/s00355-019-01227-0 . hal-02374903

\section{HAL Id: hal-02374903 \\ https://hal.umontpellier.fr/hal-02374903}

Submitted on 25 Nov 2019

HAL is a multi-disciplinary open access archive for the deposit and dissemination of scientific research documents, whether they are published or not. The documents may come from teaching and research institutions in France or abroad, or from public or private research centers.
L'archive ouverte pluridisciplinaire HAL, est destinée au dépôt et à la diffusion de documents scientifiques de niveau recherche, publiés ou non, émanant des établissements d'enseignement et de recherche français ou étrangers, des laboratoires publics ou privés. 


\title{
On discrimination in health insurance
}

\author{
Thomas Boyer-Kassem, Sébastien Duchêne ${ }^{\dagger}$ \\ preprint - forthcoming in Social Choice and Welfare
}

\begin{abstract}
In many countries, private health insurance companies are allowed to vary their premiums based on some information on individuals. This practice is intuitively justified by the idea that people should pay the premium corresponding to their own known risk. However, one may consider this as a form of discrimination or wrongful differential treatment. Our goal in this paper is to assess whether profiling is ethically permissible in health insurance. We go beyond the existing literature in considering a wide range of parameters, be they genetic, non-genetic, or even non-medical such as age or place of living. Analyzing several ethical concerns, and tackling the difficult question of responsibility, we argue that profiling is generally unjust in health insurance.
\end{abstract}

\section{Introduction}

In many countries, private health insurance companies are allowed to vary their premiums, or to reject applicants, based on some information they collect on individuals. This is the case in the United States, United Kingdom, Switzerland and France among others. ${ }^{1}$ For instance, the companies can propose higher premiums for people with higher cholesterol rates. One intuitive economical justification for this practice is that people should pay the premium corresponding to their own known risk. If having a high cholesterol rate increases the risk of a cardio-vascular disease, and hence expected health care costs, then the premiums should be adapted accordingly. Such linking of risk factors and health care costs (for short: health costs) is known as "health profiling" (or "health risk adjustment"). Risk factors may be as diverse as: medical history, smoking habits, alcohol consumption, age, or even genetic factors. ${ }^{2}$ Note that profiling can be implemented without assuming that correlation

*Université de Poitiers, MAPP, Département de Philosophie, 36 rue de la Chaîne, F-86000 Poitiers, France. E-mail: thomas.boyer.kassem@univ-poitiers.fr

${ }^{\dagger}$ CEE-M, Univ. Montpellier, CNRS, INRA, Montpellier SupAgro, Montpellier, France. Email: sebastien.duchene@umontpellier.fr

${ }^{1}$ France has exceptions: "mutuelles", which are not-for-profit health insurance companies, are not allowed to implement some profiling based on medical criteria. However thay can profile on age or place of living. French for-profit health insurance companies are allowed to profile on medical criteria.

${ }^{2}$ Profiling on genetic information has been forbidden in the US since 2008 . Cf. https://www.genome.gov/24519851/ In Australia, profiling is illegal for "health status, age or claims history". Cf.

http://www.health.gov.au/internet/main/publishing.nsf/Content/Frequently + Asked + Questions-1 
means causation, and an instrumental use of correlation is sufficient. For instance, the place of living may be used to profile if a correlation is observed with health costs, even if the company is aware that there may be some confounders. Profiling in health insurance can be considered as a "statistical" discrimination if it is based on scientifically established statistical correlations, and we shall assume this here.

Health bills and premiums are a major issue for people in many countries. For instance, nearly 2 million people a year in the US declare bankruptcy because of unpaid medical bills (Mangan 2013). Moreover, profiling in health insurance can lead to denial of insurance altogether to people whose risks are so high that insuring them is unprofitable. Note also that profiling in health insurance is not a concern for optional insurances only. In Switzerland for instance, profiling on age and on place of living is implemented for the compulsory basic health insurance. So, assessing the ethical permissibility of health premiums is a pressing issue. Health discrimination is wrongful for a broad range of parameters, one may argue, because it makes people pay more on the basis of characteristics over which they have no control ("I can't be blamed for this"), which are group characteristics only ("judge me, not my group") and because it amounts to a double punishment ("I'm already ill, and now I have to pay more").

Our goal in this paper is to assess the above arguments in order to evaluate whether profiling in health insurance is ethically permissible. A standard remark by economists is that when discussing profiling in insurance, one first needs to specify whether insurance is compulsory or optional. Indeed, if profiling is forbidden when insurance is only optional, people with low health risk might decide not to enroll in insurance companies, while high risk subjects will take out insurance, knowing that they will not pay a high price for their risk. This could push up premiums significantly and ultimately lead to a breakdown of the insurance market. For that reason, risk adjustment - i.e. profiling — is generally considered to be economically necessary when insurance is not compulsory. Although we do not address in this paper the question of whether profiling in health insurance is economically justified for an insurance company, we indeed need to specify whether we consider insurance to be compulsory or also optional. Firstly, we include the case where insurance is compulsory, like in France (where it is managed by a public system), in Switzerland (where it is managed by private companies only), or in the United States (where it has been compulsory for a large part of Americans since the Obamacare, through private companies). Secondly, we also include the case where insurance is optional, but subsidized by the State, like in Australia (where the State pays a part of the premium when the insured goes in the private sector) or in Canada (where the subsidies are indirect, through a tax reduction for employees who subscribe to health insurance benefit plans). The subsidy condition that we impose in the optional case is meant to avoid the bankruptcy of the system or the increase in contributions that has been discussed above. The general idea is that State subsidies would (i) prevent that low-risk individuals no longer subscribe to private insurance by offering them an attractive premium, and (ii) dynamically compensate for potential increases in average health costs for the company in the event that some low-risk individuals still leave the private insurance. Further details and calculations would be necessary to determine the specific amounts of ideal subsidies, but this is at least a possible mechanism that a State may want to implement, and this suggests that our dis- 
cussion in this paper is potentially not limited to countries where health insurance is compulsory. Summing up, we are concerned here with the ethical permissibility of profiling in health insurance, whether public or private, and whether compulsory or optional with subsidies. This currently covers a wide range of countries. Unless stated otherwise, we shall assume for simplicity that the insurance companies reimburse all health costs.

Our problem can be reexpressed slightly differently, with the term "discrimination". It refers to the "acts, practices, or policies that impose a relative disadvantage on persons based on their membership in a salient social group" (Altman 2016; see also Lippert-Rasmussen 2013), which can be morally wrong when this differential treatment is based on irrelevant factors so that people are differentially treated for no good reason. The question then becomes whether statistical facts about a group (for instance, people with a specific medical history) have relevant justificatory force in treating members of that group differently than others (requiring them to pay higher premiums).

In the literature so far, the debate on discrimination in health insurance has been mainly on whether insurances should be allowed to use genetic information (Hellman 2003, 2008, Moreau 2010, Lippert-Rasmussen 2015b). Our scope is wider, and for instance we shall consider that the information which the insurance company may use can be genetic or not, medical or not. More precisely, the list of parameters we shall consider here consists in: present diagnosed illness (such as diabetes or heart failure), medical history, body mass index, smoking habits, alcohol consumption, genetic information, gender, age, race, sexuality, place of living, income. Overall, a health insurance company might want to rely on scientifically established statistical correlation between any of the parameters from the above list and health costs. For instance, if parameter $X$ is observed to be correlated with higher health costs per year, for whatever reason, then profiling entails that the premium for people with parameter $X$ increases.

A remark on the parameters "age" and "income" is needed so as to remove a possible misunderstanding. ${ }^{3}$ What we are considering in this paper is the possibility that an insurance company varies the premium based on the correlations between a parameter, e.g. age or income, and health costs and we assess this profiling from an ethical perspective. What we are not concerned with is whether it is ethically permissible to vary the premiums depending on that same parameter in the absence of any observed correlation with health costs, and for some other ethical reasons. For instance, we do not address the question whether children should pay less because they are children (in a family-supportive like policy), or whether people with higher incomes should pay more because they have higher incomes (in a re-distributive fashion). Regarding income for instance, we only consider the question whether people with higher incomes should pay less because income is negatively correlated with health costs. Then, the reader is free to use the theory of her own on the redistributive question, and to combine it with our thesis. In other words, when we say that profiling is not ethically permissible for age or income, we are not saying that premiums should not vary with age or income simpliciter.

Our thesis is twofold. First, profiling on parameter $X$ is ethically acceptable

\footnotetext{
${ }^{3}$ Thanks to an anonymous Referee for suggesting that we include the parameter "income" with the distinction discussed below in mind.
} 
only in case agents are responsible for the costs associated with $X$ (and not only for $X$ ). This condition can be further specified in requiring that (i) the agent is responsible for $X$, (ii) $\mathrm{X}$ is causally linked to health costs, and (iii) the agent can reasonably be expected to know that (ii). If at least one of these conditions is not met, the same premium should be offered regardless of the person's value of this parameter. We consider these conditions as necessary for the ethical acceptability of profiling on $X$, but do not argue that they are sufficient. Second, no parameter from our list actually fulfills these conditions. So, we conclude that profiling in health insurance is a form of unfair discrimination in all the cases we discuss. Note that our thesis is ethical only. We are not concerned with its practical implementation in policy - this question would need another paper. Therefore, we do not discuss any practical implications resulting from our ethical conclusions whether for optional or compulsory health insurance.

The scope of our conclusion is new in the literature. In his no-profiling thesis, Lippert-Rasmussen (2015b) also discusses choices and responsibility. However, that paper only considers medical information, and relies on a luck egalitarian view (Lippert-Rasmussen 2015a). Here, we take a broader perspective, including nonmedical information that is correlated with health costs, and not restricting ourselves to a luck egalitarian view. We start in Section 2 by a tour of ethical theories to guide our discussions. In Sections 3 and 4, we tackle the question of responsibility.

\section{Ethical concerns with profiling in health insur- ance}

This Section considers various ethical concerns with profiling in health insurance. Which reasons can one have to object to profiling? Does it fail to maximize total utility? Does it violate equality of opportunity? Does it harm the worst off? Can't it be justified behind a Rawlsian veil of ignorance? We raise these concerns, and connect them to dominant ethical theories. Methodologically, we choose not to endorse here one particular ethical theory, but show how profiling raises various valid - utilitarian, egalitarian, prioritarian and contractualist - concerns. Our pluralist approach analyzes the various ethical concerns raised by profiling, each of which can plausibly claim to have normative weight. For reasons of space, we limit ourselves to the most central concerns and do not claim to capture all relevant subtleties of different ethical theories.

Before reviewing in some details the various ethical concerns mentioned above, let us briefly consider libertarianism. Because libertarians insist on freedom of choice and on the idea that people are morally entitled to their resources, in particular the money they own, it is hard to see how they could support a no-profiling thesis which compels agents to some form of risk sharing and money redistribution. For libertarians, agents have the right to accept, and companies to offer, health insurance contracts with any terms, in particular with some profiling. Libertarianism seems to be the only moral theory which clearly opposes no-discrimination positions. A branch of libertarianism, however, might not agree with this line of reasoning so-called left-libertarianism. As someone's genes are given by Nature, not by her own labour, and hence are a form of natural resources, if you think that receiving 
less from a natural resource violates your right to an equal share of that natural resource, as left libertarians do, you then become sympathetic to the idea that brute luck health factors should be neutralized, and that profiling in health insurance might not be fair after all. This is how left libertarians would oppose some profiling in health insurance. Let us now turn to other moral theories in more details.

\subsection{Utilitarian concerns}

In a utilitarian framework, one should maximize the total sum of individual utilities. Let us compare a world, called NP, in which only companies which do not profile exist, and a world called $\mathrm{P}$ in which only companies which profile exist. Assume first that the insurance companies simply redistribute the same total health costs, i.e. they make no profit and no loss on average - the risk is just shared among all agents. If an agent's utility depends exclusively on the money she gains and loses, the sums of expected utilities are the same in both worlds. In other words, profiling seems to raise no specifically utilitarian worries. And this conclusion can be generalized in the case companies do not simply redistribute the same total health costs, but charge a given amount for their running costs or their profits. ${ }^{4}$

Now, total utility plausibly does not depend only on the monetary gains and losses of individual agents but also on that of insurance companies. Profiling itself can be extremely costly to the insurance companies. Collecting private data on individuals and making statistical analyzes require significant technical and human resources. Also, profiling can generate costly disputes about whether there were pre-existing conditions that made people ineligible for the insurance they chose. Therefore, profiling is costly to the insurance company, and in turn to the agents.

In addition, money is not all that matters. People who have to pay more as the result of profiling, e.g. for being in overweight, may feel discriminated against and stigmatized. Also, whether people are happy with paying specific premiums depends on what they get in return. Imagine two people paying the same premium: A falls ill but $\mathrm{B}$ does not. Does it make sense to assume that the utility loss of A's sickness is compensated for perfectly by the reimbursement from the insurance? And what about B who pays the premium but never gets reimbursed because she does not fall ill? She loses money but does get a sense of security.

Let us therefore extend our simple framework and assume that three factors matter for well-being (or utility for that matter):

1. money (which you lose when paying premiums and health care costs, but the latter can get reimbursed);

\footnotetext{
${ }^{4}$ All this actually depends on the assumption that individual utilities are linear with premiums. What if utilities are concave, i.e. if the agents' marginal utilities of money are decreasing? Assuming for simplicity that agents have equal income, it is easy to see that the total sum of utilities are then lower in the $\mathrm{P}$ world than in the NP world, because the extra money which is left to agents in good health contributes less in utility terms. In other words, utilitarianism sides against profiling in that case. Conversely, if the utility function were convex, utilitarianism would side for profiling. Then, are utility functions of real agents convex, concave, or linear? Empirical data on the shape of the utility function are not consensual: in experiments, some individuals display concave functions, others display convex or linear, and there seems not to be a "typical" profile (Kahneman and Tversky 1979, Abdellaoui et al. 2007, Abdellaoui et al. 2008, Abdellaoui et al. 2013). So, it is not clear which function we should consider here, and we do not enter this complication.
} 
2. health (which can be lost but also restored when health care costs are made);

3. psychological and emotional costs (such as a sense of security, or feelings of unfairness and stigmatization).$^{5}$

In this extended framework, the only difference between NP and P worlds will lie in the third factor. Assume for simplicity that agents are either sick or healthy. In utilitarian terms, a psychological or emotional cost that an agent associates with a positive value will technically increase the total utility (of either NP or P worlds), and hence receives a positive utility. Conversely, a cost associated with a negative value receives a negative utility. The potentially sick may feel stigmatized in the $\mathrm{P}$ world (negative utility), while the potentially healthy will have a sense of security (positive utility) and may have a feeling of unfairness (negative utility) since they pay for the sick. Overall, it is not clear where the total sum of utility will head, unless we make specific assumptions about the values of the utilities associated with psychological costs. The value of this extended framework, however, is to reveal the uneven distribution of utility losses and gains. In a $\mathrm{P}$ world, the sick will suffer from utility losses that are not only health-related (obviously) but also money-related and stigmatization-related. In a sense, profiling in health insurance triples the harm inflicted on the sick, who are worse off not only in terms of health but also money (their premiums are higher in a P world than in an NP world) and psychology (they feel stigmatized). Conversely, in an NP world, the healthy basically sponsor the treatments of the sick, more evenly distributing utility. However, such distributional concerns are best expressed not in utilitarian but in prioritarian and egalitarian terms, to which we turn below. These approaches have the advantage that they do not require us to make a hypothetical guess of the above values of the utilities associated with psychological costs.

To summarize the utilitarian approach, if we only consider money (item 1) and health (item 2), and assuming linear utility functions, the overall cost remains the same in both worlds, and NP and P are morally equivalent. The only difference is in the redistribution of the total utility within the population at the individual level. But considering the profiling cost for the company makes the utility - and hence, moral - balance tip towards NP. Now, if psychological and emotional costs (item 3) are included, it is essential to precisely and quantitatively define this notion. Note that the definition and the scope of these costs are quite subjective, since individuals may feel different emotions or costs depending on their medical histories, psychological profiles and health status (Finkelstein et al 2009). However, the addition of this third item does not help us to rule on the issue of profiling within utilitarianism. This is why we now turn to other ethical concerns.

\subsection{Prioritarian concerns}

A second set of concerns with profiling in health insurance is that it makes the worst off even worse off. When speaking of "worst off", two main variables may

\footnotetext{
${ }^{5} \mathrm{~A}$ feeling of stigmatization can occur for people in poor health, like in "I'm pointed at because of my obesity". Admittedly, stigmatization may not occur for profiling on age. But all other parameters in our list are potentially concerned. On the other side, some people in good health may have a feeling of unfairness, like in "I shouldn't be paying for those people in bad health".
} 
be considered: health and money. A simplification comes from the fact that these two variables are strongly positively correlated (Marmot 2005): on average, people in poorer health also are people with lower incomes or lower wealth. The general prioritarian idea that it would be unjust to make the worst off even worst off, can be made precise is different ways.

Leximin prioritarians believe that inequalities - e.g. paying different premiums are just only if they improve the situation of the worst off. Take Rawls's Difference Principle, which states that "social and economic inequalities are to be arranged so that they are [...] to the greatest benefit of the least advantaged" (Rawls 1999, p. 95). In our problem, the least advantaged are those with high health risk, or in poor health for short. Since inequalities should be arranged to their benefit, they should at least not be charged more than people with low health risk, or in good health for short, and this speaks against profiling.

Other prioritarians argue that the same incremental well-being gains should be given more moral weight when they go to the worst off than when they go to the better off (e.g. Adler 2011). Here too, profiling is unjust because it further worsens the situation of the worst off while benefiting the better off. In a $\mathrm{P}$ world, those in poor health will see both their wealth and health decrease. In an NP world, at least the worst off (in terms of health) are not made worse off (in terms of money, compared to the healthy). If any differential treatment is called for on prioritarian grounds, it is a form of inverse profiling, with the sick paying lower rather than higher premiums, which would improve their situation compared to a $\mathrm{P}$ world.

The idea that profiling constitutes an unfair treatment of the worst off is basically a reformulation of the idea that it constitutes a triple punishment on the sick, or on people with high health risk. First, agents in poor health already pay a penalty by being in poor health. Second, they are charged more because of profiling. Third, they suffer emotional costs through stigmatization. Note further that having a triple punishment is somehow orthogonal to usual conceptions of justice and the way it works in other areas. For instance, someone in jail usually does not pay for the cost of her prison stay in addition to being deprived of liberty, and furthermore is offered reintegration plans.

\subsection{Contractualist concerns}

Contractualists like Rawls and Scanlon argue that ethical concerns arise from a (hypothetical) contract between agents. Rawls uses his famous "veil of ignorance" thought experiment to argue that rational parties in the original position would agree on justice principles that ensure the best possible situation for the worst off. If you do not know which situation you will end up in (e.g. whether you will be in poor or in good health), you will only favor inequalities (1) that arise from fair equality of opportunity (see Section 2.4) and (2) that improve everyone's situation, including the worst off. As such, we would all see the injustice of requiring those in poor health to pay more, because we might as well end up in that situation (once the veil of ignorance is lifted and the distribution of health benefits is known). Profiling would not pass this contractualist test of justice. It would indebt the sick and likely turn them into a permanent underclass. Trapping them into poverty, profiling would generate a vicious cycle of bad health and less wealth, which besides 
obvious utilitarian (2.1) and prioritarian (2.2) worries, will not be consented to from the impartial point of view of Rawls's original position.

Now take the contractualist approach by Thomas Scanlon, according to which acts and policies are to be judged by moral principles, and these principles only hold if no one could reasonably reject them. "In order for a principle to be reasonably rejectable there must be some relevant standpoint from which people typically have good reason" to refuse that this principle be used by themselves or by others (Scanlon 1998: 218). Consider profiling, i.e. adapting premiums according to the agents' risk profiles. People in poor health could reasonably object to this principle, for reasons mentioned before: it amounts to a triple punishment. Conversely, it would not be reasonable for healthy people to oppose a no-profiling principle on the basis that they are paying slightly higher premiums. ${ }^{6}$ Scanlon's contractualism thus seems to conclude that the sick have legitimate grounds for complaint, which adds to the conclusion that profiling is ethically impermissible.

A general feature of contractualism is that individual benefits and burdens should not be aggregated and that utilitarians neglect what Rawls (1999) calls the "separateness of persons". Ashford and Mulgan (2012) express this as saying that contractualism "does not allow a number of lesser complaints to outweigh one person's weightier complaint". Compare this with the utilitarian approach in Section 2.1. If we assume that agents' utility functions are convex, then high premiums have comparatively less weight than low ones. When all individual utilities are added, profiling gives a higher collective utility than no profiling. Contractualists disagree: the fact that some persons have to pay an excessively high premium is sufficient to reject profiling, even though others benefit from paying a low premium with a relatively higher individual utility. This corresponds to the prioritarian insight that gains (and conversely, burdens) for the worst off have more moral weight than gains (and burdens) to those better of.

Since the rejection of a principle can be based on reasons not related to well-being or utility, contractualist concerns are not consequentialist. "I might reject a principle that arbitrarily exempts some people from a burden borne by everyone else, on the grounds that such a principle treats me unfairly - even if the alternative is a principle that places that burden on everyone." (Ashford and Mulgan 2012) The relevance to profiling in health insurance should be clear: paying more can be considered unfair to those in poor health because of consequentialist reasons (it amounts to a triple punishment on the part of the sick), and non-consequentialist reasons (the sick are not responsible for being ill; more on this in Section 3).

\subsection{Egalitarian concerns}

Egalitarian concerns about profiling are diverse, basically because of the variety of egalitarian theories, each of which provides a different answer to the question: equality of what? Utilitarian or more broadly welfarist theories can be understood as egalitarian (each unit of utility or welfare is taken into equal consideration) and so can contractualist theories (each person is given equal respect, an equal position in the contractualist scheme). Or one could favor equalizing health, but this is

\footnotetext{
${ }^{6}$ Section 2.4 provides other reasons by Scanlon not to oppose no-profiling, this time from an egalitarian viewpoint.
} 
irrelevant if we assume that insurance companies reimburse all health costs. Or one could favor equalizing access to health care, which obviously speaks against profiling, which makes access to health care depend straightforwardly on health risks. Or one could favor equalizing wealth, which holds that the situation in which people's wealth (or spent money) are more equal should be preferred. Again, profiling goes against such an egalitarian theory.

A widespread egalitarian theory is resourcist and stresses that justice requires equalizing everyone's resources (rights, liberties, primary goods but also wealth and opportunities). Such responsibility-sensitive luck egalitarian theories argue that what people do with these resources is up to them. We will treat them, and their relevance to profiling in health insurance, more extensively in Section 3.

Closely related is capability theory, according to which everyone should have (equal or at least basic) capabilities or effective opportunities to do and be what one wants to (Robeyns 2005). In a P world, the sick do not benefit from the redistribution that would characterize an NP world and ultimately end up with substantially less capabilities than the rich, even to the extent that their most basic capabilities (like bodily health; Nussbaum 2006) are no longer met.

Another promising theory is social egalitarianism, which stresses that in a just society, everyone can relate to each other 'as equals'. Instead of trying to equalize a specific 'currency of justice' (like utility, welfare, resources or capabilities), authors like Samuel Scheffler and Jonathan Wolff see equality in social or relational terms. Again, profiling seems hardly defensible, as it is stigmatizing to those in poor health. ${ }^{7}$ Also, as the abovementioned vicious cycle between health inequalities and economic inequalities traps (a lot of) sick people into poverty, they are increasingly marginalized and effectively inhibited from relating to others as equals.

Finally, one can, like Scanlon $(1996,2018)$, refer to multiple reasons to object to inequality, none of which assume that such inequality is intrinsically bad. The inequalities arising from profiling in health insurance can be objected to because they ultimately result in suffering (with some sick people no longer able to pay their health costs), because they give rise to problematic status relationships of superiority and inferiority (with sick people being stigmatized), because they give rise to unequal playing fields and thus unequal opportunities in multiple domains (like unequal economic opportunities in the job market) and undermine the procedural fairness of procedures in important basic institutions (like equal access to basic health care), because it gives healthy people who pay less a higher degree of control on their lives and indirectly over the lives of those who are sick and who pay more, because some sick people could not afford health insurance and medical care anymore, which would give the interest of sick people less weight than other people (and thus violate the equal concern requirement), and finally because there is no desert for being in good health (more on this in Section 3).

The conclusion that profiling raises serious egalitarian concerns thus holds across the board. Regardless whatever should be equalized, a $\mathrm{P}$ world raises ethical worries that an NP does not.

\footnotetext{
${ }^{7}$ As indicated in footnote 5 , age seems to be the only parameter from the list for which stigmatization does not occur.
} 


\section{What about responsibility?}

One might object that the analysis of the previous Section is too rough: all parameters $X$ that could be used in profiling have been treated equally, whereas they are not equal from an ethical viewpoint. Some cases of poor health seem to result from deliberate choices, for which people bear responsibility. For instance, as the health risks of smoking are common knowledge nowadays, someone who smokes can be held responsible for this behavior and can thus be required to bear its consequences. It would be unfair to have others pay for one's choices. If someone chooses to take a risk, she should be prepared to pay for it. So, the objection goes, ethical considerations regarding responsibility not only allow but even require profiling on those parameters for which people bear responsibility. This objection is in line with moral theories for which a core distinction should be made between what results from pure bad luck and what results from an agent's choice (e.g. along Dworkin's 2000 line). Depending on the specific distributive principle endorsed, this can yield theories such as luck egalitarianism or luck prioritarianism. For instance, luck egalitarianism (Lippert-Rasmussen 2015a), considers that inequalities (e.g. paying a higher premium) are just when they arise from choices (option luck). Luck egalitarians generally argue that resources (such as money) should be distributed equally at first but that inequalities may legitimately arise through people's choices (such as people with unhealthy lifestyles paying more for their health care).

We agree that responsibility is indeed crucial in assessing fairness, and we are ready to grant the point made by luck egalitarians, luck prioritarians, or other luck sensitive theories. What we want to point at, however, is that the question of responsibility in health insurance is more complex than the above objection seems to assume. As a starting point, let us specify what is meant by "responsibility" with the following classical definition: an agent is responsible for $Y$ if $Y$ is a result, foreseeable by the agent, of a free choice of hers. ${ }^{8}$ This definition can be refined by acknowledging that forseeability and freedom of choice come in degrees, and hence responsibility too. In our problem, a first distinction is that responsibility can bear on two things: the value of a parameter $X$ (e.g. I smoke), and the associated health costs (e.g. the cost of my chemotherapy in case I have a lung cancer). We consider responsibility for $X$ in this Section, and responsibility for the costs in the next Section.

Recall the list of factors we consider in this paper (cf. Section 1): present diagnosed illness, medical history, body mass index, smoking habits, alcohol consumption, genetic information, gender, age, race, sexuality, place of living, income. Few people would consider that one is responsible for one's genes, gender, age, race, or sexuality. The most plausible candidates from the list to pertain to one's responsibility are then five: body mass index (BMI), smoking habits, alcohol consumption, place of living, and income (plus diagnosed illness and medical history insofar as they are linked to these parameters). According to the responsibility objection presented above, profiling on these parameters is fair because agents can be held responsible of

\footnotetext{
${ }^{8}$ By "free choice", one could require that the options faced by the agent are sufficiently varied with respect to $Y$, or that they are not all as bad. Then, one would consider that a worker who is only offered a job in a mine with asbestos or a job in a factory with chemical vapors, and who chooses the former, is not responsible for developing lung cancer.
} 
them and of related health costs. A general theme of our answer is that the responsibility problem is more complex than sketched above. In particular, not all of these five parameters should be dealt with in the same way. We group together the first three - BMI, smoking habits and alcohol consumption - as they involve addictive behaviors, and we discuss them in this Section, distinguishing between theoretical (Section 3.1) and pragmatic (Section 3.2) issues. Place of living and income are discussed in Section 4.

\subsection{A theoretically complex issue}

One should start by acknowledging a theoretical complexity. Smoking, drinking, and food habits that can increase your body mass index, are unhealthy lifestyles which are addictive. And it is scientifically well-established that (i) genetic predispositions (Agrawal and Linskey 2008, Kreek et al. 2005, Rankinen et al. 2005, Stice et al. 2008, Wang et al. 2004, Bochukova et al. 2010, Grimm and Steinle 2011) and (ii) environmental factors play an important role in these three points. It has been clearly shown that a wide variety of environmental factors, such as social, cultural, physical and familial environments, have a strong and significant impact on drug addictions (Rhodes et al. 2003) and body mass index (Bishop et al 2005, Borengasser et al., 2014). For example, Whitesell et al. (2013) highlight how familial risk factors - such as childhood maltreatment, level of parental education, familial socio-economic status - can increase risk of drug consumption for adolescents. Physical and sexual abuse, emotional abuse, but also social influences or deviant peer relationships are non-exhaustive factors that explain drug use (for reviews, see Hawkins et al. 1992, Whitesell et al. 2013). Concerning the BMI and obesity, Christakis and Fowler (2007) show that the risk of being, or even becoming obese, is significantly higher for subjects with "obese family members or peers in their social networks". This phenomenon is known as "social clustering" and could be explained by "similar social norms" and by an induction process between individuals that favor the spread of obesity. Genetic, psychological and environmental factors greatly influence the BMI and food habits (for a review, see Richter 2016).

Genetic and environmental factors are clearly out of the scope of people's responsibility — one doesn't choose one's genes, nor the socio-economic status of one's parents. ${ }^{9}$ The importance of these factors is not anecdotal. For instance, the genetic predisposition is estimated to account for around $50 \%$ of alcohol addictions (Gierski et al. 2013) and between 50 and $80 \%$ of the BMI (Allison et al. 1996, Bell et al. 2005). ${ }^{10}$ There are also some vicious circles and reinforcement processes.

\footnotetext{
${ }^{9}$ Compatibilists $\grave{a}$ la Frankfurt could object that, even if an act, e.g. smoking, has some genetic origin, a person is responsible for this act as soon as she embraces (at a second-order level) her addictive desire to do that act, e.g. if she wants to follow her smoking desire and does not want to resist it. However, this objection can be partly theoretically answered by noting the vicious circles that might determine her second-order volition, as discussed hereafter. Moreover, important practical difficulties would arise if profiling was to be implemented only for responsible persons how could companies identify those willing addicts?

${ }^{10}$ One may object that in criminal law for instance, the responsibility of alcoholics is not discounted in this way. To this, we reply first that the law in many countries may not have adapted quickly enough to recent scientific findings, second that the moral responsibility in which we are interested here may not correspond to the legal responsibility (and it is a matter of ongoing debate whether it should).
} 
For example, drinking a lot can affect one's abilities, such as memory, impulsivity, or decision-making and increases the need to drink (Cabé et al 2016). Studies on neuronal and hormonal functioning have also shown some addictive processes in the appearance and maintenance of obesity and in addictive-like eating behaviors (Gearhardt et al. 2011, Murray et al. 2014). These processes are close to drug addictions (Volkow and Wise 2005) and affect subjects' behaviors and emotions (Parylak et al. 2011), generating reinforcement processes. Then, an initial responsibility can only diminish as time goes (ceteris paribus). In addition, some psychiatric disorders, for which people cannot be held responsible, do have some effects on health. For instance, schizophrenic persons in acute delirious episodes can become disinterested in topics considered relevant for "living a healthy life", or put themselves into physical danger. Note finally that the knowledge of the causal influence of each factor is not sufficient to assess someone's responsibility. Interactions between the various factors are known to be crucial in triggering an addiction (for instance, a genetic predisposition requires some environmental factor to be active). So one needs to know much more to attribute individual responsibility.

Overall, this gives several theoretical reasons why it is not possible to simply consider that an individual is fully responsible for a parameter related to addictions on which profiling could be implemented, and hence that it would be fair to do so. Free will is just not the only ingredient there. ${ }^{11}$ One might reply that the causal influence of genetic and environmental factors can be assessed, and that the premiums should vary according to what remains of one's responsibility. Unfortunately, this suggestion raises important pragmatic difficulties, that we discuss next.

\subsection{Pragmatic difficulties}

We now argue that assessing the causal influence of genetic and environmental factors for smoking, drinking, and BMI, in order to remove that part from the responsibility of agents, is not pragmatically feasible for health insurance companies. First, consider genetic factors. ${ }^{12}$ Current knowledge of the causal influences of genetic factors is only at its beginnings, and is not very precise yet. For example, the influence of genetic factors on alcoholic addiction is known with large uncertainties: "between 40 and 60\%" (Gierski et al 2013) and between 50 and $80 \%$ for the BMI (Allison et al. 1996, Bell et al. 2005). Which rate would it be fair to consider for profiling? Admittedly, one might consider that these uncertainties at least suggest a lower bound for agents' responsibilities, for instance $20 \%$ for the BMI. But other problems arise. Second, identifying the causal influence of environmental factors (e.g. of having an alcoholic father or an obese mother) is even much more complex, and existing data are even less precise. Third, assessing the level of interaction between genetic and environmental factors adds a high degree of complexity. Fourth, these studies on environmental factors are epidemiological and concerned with av-

\footnotetext{
${ }^{11}$ In the philosophical literature on addiction, the position we are defending here might actually seem like a truism. For instance, Wallace (1999) needs to write a whole paper to argue that volition plays at least some role in the actions of an addicted person, against those who hold a mechanistic conception of addiction, where actions are determined by desires.

${ }^{12}$ Note that the form of genetic profiling which is considered here is the opposite of the kind usually discussed in the literature: here, genetic factors are used to argue that premiums should not be raised.
} 
erages, whereas the responsibility argument requires the assessment of individual responsibility. A precise individual responsibility cannot automatically be inferred from (imprecise) averages. For instance, even if we knew that having an alcoholic father (an obese mother) accounted for alcoholism (obesity) at the rate of $30 \%$ on average, this would not imply that Mr. Y's responsibility is reduced by $30 \%$ because of his alcoholic father (his obese mother). Perhaps, in his particular situation, related to personal circumstances and history, his responsibility is actually reduced of $10 \%$, or of $50 \%$. It is not enough that the insurance company is fair on average, because the argument of responsibility is precisely made at the individual level.

One might suggest that the insurance company could go beyond epidemiological medical studies, and launch studies of environmental factors of their would-be clients to assess their individual responsibilities. But this would be very difficult if not impossible (how assess the precise influence of Mr. Y's alcoholic father, or obese mother?) and very costly. Furthermore, these individual inquiries could be opposed on privacy grounds (with reasons based on other moral values than justice or fairness). For instance, egalitarians could argue that inquiring in great detail into people's intimacy would fail to treat them with the respect that is equally due to all human beings.

If implemented, profiling can raise premiums dramatically and this can have dire consequences on individuals. Given our previous point about the financial and emotional harms of profiling on those who are already in poor health, we believe a cautious attitude should be adopted: without high-standard proofs of someone's individual responsibility about parameter $X$, profiling on $X$ should not be implemented. A kind of presumption of innocence should prevail.

This cautious approach can be re-expressed as a value judgment between two possible kinds of errors: either charging high fees for individuals who are not responsible for the value of parameter $X$, or charging only slightly higher fees for all individuals, some being responsible and some being not. We believe the latter situation is preferable when knowledge is sparse and responsibility cannot be assigned with enough confidence. It would be morally wrong to charge someone very high fees without being sufficiently sure that she is responsible. As we have argued above, the knowledge that health insurance companies can reasonably hope to have on individual responsibilities is very low and imprecise on many parameters. As a consequence, the cautious approach we embrace recommends that profiling should not be implemented for these parameters (smoking, drinking, and BMI).

To sum up, we have argued that for three out of the five parameters, there are theoretical problems in considering that agents are responsible for the values of the parameters, or pragmatic problems in assessing these values. We discuss the last two parameters, place of living and income, in the next Section, within a more general consideration.

\section{Responsibility and causality}

The previous section has discussed the responsibility of an agent towards the value of a parameter $X$. As indicated, this is not the whole story of responsibility: what matters in the end (according to the objection mentioned at the beginning of Section 3) is her responsibility for the health costs. It is because the agent is 
responsible for increased health costs that it would not be fair for others to pay for these extra costs. This leads us to consider now the relation between $X$ and associated health costs.

So that the responsibility of the agent extends to health costs, and not just to $X$ (e.g. so that the responsibility of the agent extends to the cost of her chemotherapy, and not just to her being a smoker), health costs need to be foreseeable by the agent, according to the classical definition adopted in Section 3 (an agent is responsible for $Y$ if $Y$ is a result, foreseeable by the agent, of a free choice of hers). This forseeability requires two things: that there is a causal connection between $X$ and the costs (so that choosing $X$ does make a change in the costs), and that the agent knows this connection. So, correlations between $X$ and costs are not enough for a profiling to be fair, and this is in stark opposition with current profiling practices, which are just based on the identification of correlation patterns. In other words, if someone is responsible for some $X$, but that $X$ is not what makes health costs be higher, then it is unfair to charge the person more for the increased health costs. The responsibility of the person just bears on something irrelevant for health costs. For instance, suppose that there is a correlation between soccer match attending and increased health costs in one's life. Attending to soccer matches $(=X)$ can be considered as a deliberate choice, on which one's responsibility is not in doubt. But would it be fair to profile on this parameter in health insurance? No, because there is no causal relation between attending a soccer match and having a poorer health. I'm not suddenly changing my health when attending a soccer match; instead there are some confounders, like belonging to some social class.

A slight improvement on the forseeability condition should be mentioned. ${ }^{13}$ Requiring that the agent knows the causal connection between $X$ and the costs is a bit too strong: it excludes the case of voluntary ignorance for which an agent can be held responsible. For instance, if someone refuses to listen to her doctor about the links between smoking and cancer (and hence, various costs), then she doesn't know the causal connection, but our intuition is that this is not enough to morally forbid profiling on smoking for this agent. So, a better knowledge requirement is that the agent can reasonably be expected to know the causal connection.

Summing up with previous Section 3, we can now claim that there are three necessary conditions for a profiling on $X$ to be fair:

(i) the agent is responsible for $X$,

(ii) $X$ is causally linked to health costs,

(iii) the agent can reasonably be expected to know that (ii).

This can be summed up in the formulation that a profiling is fair only if the agent is responsible for the health costs. Now, causal relations are not always of an all-ornothing nature, as the presence of a parameter can only increase the chance of an illness, and of related health costs. So, a better version of our point about causality is that profiling on $X$ is the fairer, the stronger the causal link is between $X$ and health costs. Similarly, other conditions (i) and (iii) admit degrees. A more nuanced thesis, then, is that a profiling on $X$ is the fairer:

\footnotetext{
${ }^{13}$ We thank an anonymous Referee for suggesting this improvement.
} 
(i) the more the agent is responsible for $X$,

(ii) the more $X$ is causally linked to health costs,

(iii) the more the agent can reasonably be expected to know that $X$ is causally linked to health costs.

This is the final general thesis about fairness for profiling in health insurance on which we settle. Note that according to our thesis, it would not have been fair to profile on smoking before mid-twentieth century for this reason, and it would not be fair to profile on the use of many products today for that same reason. We only claim that these three conditions are necessary for the profiling on $X$ to be ethically acceptable, not that they are sufficient. Besides, they seem not to be sufficient: suppose for instance that medical treatments are more expensive in some geographical region because of some shortage of doctors, and that I know this and that I have freely chosen to move in that region to get a more interesting job. Should I be considered responsible for my increased health costs? Our intuition is that the unjust health background structure should better be blamed. ${ }^{14}$

Note that some parameters satisfy condition (ii) and not condition (i). For instance, age is one of the causes of many illnesses, but it is not the result of deliberate choice $^{15}$. So our thesis forbids profiling on age, and requires that newborns pay as much as grownups or elderly people. This might be seen as a weird position, accustomed as we are that children usually get discounts on premiums. Does it signal that our thesis, and arguments, are wrong? No, because our thesis only bears on profiling, i.e. on variations of premiums with age based on correlations between age and health costs, not on the variations of premiums with age for reasons other than correlations, such as some social policy towards families, as we mentioned in the introduction. The reader is free to combine her own view on this latter question with our no-profiling thesis.

Let us now come back to our initial question, and investigate whether some parameters satisfy the three necessary conditions we have stated above. The previous section has excluded all parameters except the place of living (e.g. a neighborhood, a town, a county), and income. Suppose first that there is some correlation between the place of living and health costs, of which the insurance company would like to take advantage. Either this correlation comes from a causality relation (the place of living causes some increased health costs), or it does not come from one. Suppose there is a causality relation, i.e. condition (ii) is met. It must be because there is some form of pollution in the area which must cause some illness to the inhabitants, or something similar. Then it is very unlikely that some people might voluntarily choose to live there - you generally live in a polluted area because you are not rich enough to live elsewhere. So, no responsibility in this case, and condition (i) is actually not met when condition (ii) is. Suppose now there is no causality relation

\footnotetext{
${ }^{14}$ We owe this case to an anonymous Referee, who we also thank for suggesting us to clarify the necessity $v s$ sufficient aspect of our claim.

${ }^{15}$ It might be objected that one gets old in part because one does not commit suicide, which is a deliberate choice. However, committing suicide is highly correlated with psychiatric disorder (a typical figure is $98 \%$, cf. Bertolote and Fleischmann 2002), which suggests both that responsibility for suicide might not be complete and that whether to commit suicide is not a choice that sound people really consider.
} 
between the place of living and the increased health costs (condition (ii) is not met). Then it is very possible that people chose to live there (since for instance there is no pollution), and condition (i) might well be met. But overall, conditions (i) and (ii) are never met together. So, it is unfair to profile on the place of living.

Consider now profiling on income. The correlation that exists between income and health costs is a negative one, as people with lower income have poorer health (Marmot 2002), giving rise to higher health costs. Let us review each condition in turn. Is one responsible for one's income? It is doubtful that one is in a significant and direct sense: few people deliberately choose a less-paid job when given the choice, or refuse a salary rise. That is, condition (i) is at best only partially met. Is income causally affecting health? This question is hard to settle from a statistical viewpoint, because possible confounders abound, such as race, place of living, or education. It seems not to be fully established that income causally affects health, and that if it does, it does only weakly (Marmot 2002). Furthermore, a social condition like income is better viewed as a distant cause, or a "cause of cause", than as a direct cause. So, condition (ii) is at best only partially met, too. Then, can people reasonably be expected to know condition (ii)? This plausibly depends on the level of education, and hence condition (iii) is not met in general. Finally, note that conditions (i), (ii) and (iii) will hardly be satisfied simultaneously: who would consciously and freely choose a lower income job, while aware that it will deprive her health, and lead her to higher health expenditures? So we can safely conclude that profiling on income is unfair, and overall that this is so for any parameter from our list.

\section{Conclusion}

We have argued that profiling in health insurance raises substantial ethical concerns for egalitarians, prioritarians, contractualists, and possibly for utilitarians, especially if they are concerned with luck and responsibility issues. Only some libertarians would not oppose profiling. We have argued that the no-profiling conclusion holds for a large range of parameters: present diagnosed illness, medical history, body mass index, smoking habits, alcohol consumption, genetic information, gender, age, race, sexuality, place of living, income. As mentioned in the introduction, we do not take stands here on whether it would be fair for agents with higher incomes to have a higher premium, because of their higher incomes, and similarly for age. The reader may combine her own view on that question with our thesis. Because insurance companies are generally interested in profiling, it seems to us that the only way for practice to be in accordance with our ethical principles is that the law forbids profiling in health insurance, as is already done in some countries for some parameters. However, discussing precisely how to implement this ban in policy would need another paper, and we shall not attempt it here.

Some further generalization might be considered. We have assumed that the reimbursement rate is identical for everyone. What if some people would like a lower or higher coverage? Our no-profiling thesis can be reproduced for any level of reimbursement. However, the various levels of reimbursement should vary uniformly, and not be specialized on some specific illness. Otherwise, for instance, smokers would choose the special reimbursement for lung cancer, while non-smokers would 
avoid it, and this could lead to a de facto profiling.

Our general thesis might be nuanced for some voluntary (possibly punctual) practices, such as the practice of extreme sports like bungee-jumping or climbing, or traveling to dangerous countries. These practices involve higher health risks and thus higher expected health costs. Given that responsibility is clearly involved in these choices (although extreme sports may to some extent be addictive), profiling could be ethically permissible in such exceptional cases. Rather than allow profiling, however, the already current practice to require people to take additional insurances when practicing specific sports or when traveling serves the same purpose. In sum, we believe that on any plausible account of what matters ethically, profiling in health insurance is objectionable.

There is, however, an ethical viewpoint which has not been considered in this paper: paternalism, the idea that when agents are not fully rational, and their choices are not optimal, an authority (here: the State or the insurance company) can limit agents' autonomy so as to improve their choices for their own good. In the case of health insurance, paternalism could try to justify higher premiums for smoking addicts, for instance, so as to give them an additional incentive to quit smoking. But paternalism is not without raising ethical concerns of its own (e.g. could States, and even more private companies, be paternalistic?) and more fundamentally, the problem would be changed: the question would become to find which amount of increase in health premiums would best incentivize agents (as opposed to: whether the fixed increase in health premium corresponding to the fixed increase in risk is fair), and for which parameters. And note that paternalism could be implemented in ways other than by allowing profiling, e.g., by taxing cigarettes or unhealthy food.

\section{Acknowledgments}

Many thanks to Bart Engelen for his valuable contribution. We would like to thank also Marlène Guillon, Julien Cabé, Nicolas Cabé, Valérie Clément, Tom Juille, Georges Boyer, an editor of the Journal, two anonymous referees, as well as participants at the 13th conference on the International Network for Economic Methodology (San Sebastian, 2017), MANCEPT workshops (Manchester, 2019) and audiences in Poitiers (MAPP and MSHS, 2018) for useful comments and suggestions. This work has benefited from an AXA postdoctoral fellowship and support from GREDEG Nice.

\section{References}

Abdellaoui, Mohammed, Bleichrodt, Han, \& Paraschiv, Corina (2007). Loss aversion under prospect theory: A parameter-free measurement. Management Science, 53 (10): 1659-1674.

Abdellaoui, Mohammed, Bleichrodt, Han, \& L'Haridon, Olivier (2008). A tractable method to measure utility and loss aversion under prospect theory. Journal of Risk and Uncertainty, 36 (3): 245-266.

Abdellaoui, Mohammed, Bleichrodt, Han, \& Kammoun, Hilda (2013). Do financial professionals behave according to prospect theory? An experimental study. 
Theory and Decision, 74: 411-429.

Adler, M. D. (2011), Well-Being and Fair Distribution. Beyond Cost-Benefit Analysis, Oxford University Press.

Agrawal, Arpana \& Lynskey, Michael T. (2008). Are there genetic influences on addiction: evidence from family, adoption and twin studies. Addiction, 103: 1069-1081.

Allison, David B., Kaprio, Jaakko, Korkeila, Maarit, Koskenvuo, Markku, Neale, Michael C., \& Hayakawa, Kazuo (1996). The heritability of body mass index among an international sample of monozygotic twins reared apart. International journal of obesity and related metabolic disorders: journal of the International Association for the Study of Obesity, 20(6): 501-506.

Altman, Andrew (2016). Discrimination. The Stanford Encyclopedia of Philosophy (Winter 2016 Edition), Edward N. Zalta (ed.).

http://plato.stanford.edu/archives/win2016/entries/discrimination/

Ashford, Elizabeth \& Mulgan, Tim (2012). Contractualism. The Stanford Encyclopedia of Philosophy (Fall 2012 Edition), Edward N. Zalta (ed.). http://plato.stanford.edu/archives/fall2012/entries/contractualism/

Bell, Christopher G., Walley, Andrew J., \& Froguel, Philippe. (2005). The genetics of human obesity. Nature Reviews, Genetics, 6: 221-234.

Bertolote, José Manoel, and Alexandra Fleischmann. (2002) "Suicide and psychiatric diagnosis: a worldwide perspective." World psychiatry 1(3): 181-185.

Bishop, Jennifer, Middendorf, Rebecca, Babin, Tori, \& Tilson, Wilma (2005). Childhood obesity. Retrieved from http://aspe.hhs.gov/health/reports/child_ obesity/index.cfm.

Bochukova, Elena G., Huang, NI, Keogh, Julia, Henning, Elana, Purmann, Carolin, Blaszczyk, Kasia, et al. (2010). Large, rare chromosomal deletions associated with severe early-onset obesity. Nature, 463(7281): 666-670.

Borengasser, Sarah J., Kang, Ping, Faske, Jennifer, Gomez-Acevedo, Horacio, Blackburn, Michael L., Badger, Thomas M., \& Shankar, Kartik (2014). High fat diet and in utero exposure to maternal obesity disrupts circadian rhythm and leads to metabolic programming of liver in rat offspring. PLoS One, 9(1): e84209.

Cabé, Nicolas, Laniepce, Alice, Ritz, Linda, Lannuzel, Coralie, Boudehent, Céline, Vabret, François, Eustache, Francis, Beaunieux, Hélène, \& Pitel, Anne-Lise (2016). Troubles cognitifs dans l'alcoolodépendance: intérêt du dépistage dans l'optimisation des prises en charge.

L'Encéphale, 42: 74-81.

Christakis, Nicholas A., \& Fowler, James H. (2007). The spread of obesity in a large social network over 32 years. New England Journal of Medicine, 357(4): $370-379$.

Dworkin, R. (2000), Sovereign virtue. Cambridge University Press.

Finkelstein, Amy, Luttmer, Erzo FP, and Notowidigdo, Matthew J (2009), Approaches to estimating the health state dependence of the utility function. American Economic Review, vol. 99, no 2, p. 116-21.

Gearhardt, Ashley N., Yokum, Sonja, Orr, Patrick T., Stice, Eric, Corbin, William R., \& Brownell, Kelly D (2011). Neural correlates of food addiction. Archives of general psychiatry, 2011, 68(8): 808-816.

Grimm, Eleanor R., \& Steinle, Nanette I. (2011). Genetics of eating behavior: 
Established and emerging concepts. Nutrition Reviews, 69(1): 52-60.

Hawkins, J. David, Catalano, Richard F., \& Miller, Janet Y. (1992). Risk and protective factors for alcohol and other drug problems in adolescence and early adulthood: implications for substance abuse prevention. Psychological Bulletin, 112 (1): $64-105$.

Hellman, Deborah (2003). What makes genetic discrimination exceptional? American Journal of Law and Medicine 29: 77-116.

Hellman, Deborah (2008). When is discrimination wrong? Cambridge, MA: Harvard University Press.

Kahneman, Daniel \& Tversky, Amos (1979). Prospect theory: An analysis of decision under risk. Econometrica, 47 (2): 263-291.

Kreek, Mary Jeanne, Nielsen, David A., Butelman, Eduardo R. \& LaForge K. Steven (2005). Genetic influences on impulsivity, risk taking, stress responsivity and vulnerability to drug abuse and addiction. Nature Neuroscience, 8 (11): 14501457.

Lippert-Rasmussen, Kasper (2013). Born Free and Equal? New York: Oxford University Press.

Lippert-Rasmussen, Kasper (2015a). Luck Egalitarianism. London: Bloomsbury publishing.

Lippert-Rasmussen, Kasper (2015b). Genetic discrimination and health insurance. Res Publica 21: 185-199.

Mangan, Dan (2013). Medical bills are the biggest cause of US bankruptcies: study. CNBC, 25 June 2013.

http://www.cnbc.com/id/100840148

Marmot, Michael (2002). The Influence Of Income On Health: Views Of An Epidemiologist. Health Affairs 21(2): 31-46.

Marmot, Michael (2005). Social determinants of health inequalities. The Lancet, 365(9464), 1099-1104.

Moreau, Sophia (2010). What is discrimination? Philosophy \& Public Affairs 38: 143-179.

Murray, Susan, Tulloch, Alastair, Gold, Mark S., \& Avena, Nicole M. (2014). Hormonal and neural mechanisms of food reward, eating behaviour and obesity. Nature Reviews Endocrinology, 10(9): 540.

Nussbaum, Martha (2006). Frontiers of Justice: Disability, Nationality, Species Membership. Cambridge, MA: Harvard University Press.

Parylak, Sarah L., Koob, George F., \& Zorrilla, Eric P. (2011). The dark side of food addiction. Physiology \& behavior, 104(1): 149-156.

Rankinen, Tuomo, Zuberi, Aamir, Chagnon, Yvon C., Weisnagel, S John, Argyropoulos, George, Walts, Brandon, Pérusse, Louis \& Bouchard, Claude (2006). The human obesity gene map: The 2005 update. Obesity, 14(4): 529-644.

Rawls, John (1999). A Theory of Justice, Revised Edition. The Belknap Press of Harvard University Press, Cambridge MA.

Rhodes, Tim, Lilly, Robert, Fernández, Cesáreo, Giorgino, Enzo,Kemmesis, Uwe E., Ossebaard, Hans C., Lalam, Nacer, Faasen, Imar \& Spannow, Karen Ellen (2003). Risk factors associated with drug use: the importance of 'risk environment'. Drugs: education, prevention and policy, 10 (4): 303-329. 
Richter, L. (2016). Understanding and addressing food addiction: A science-based approach to policy, practice and research.

Robeyns, Ingrid (2005). The capability approach: a theoretical survey. Journal of Human Development, 6 (1): 93-117.

Scanlon, T. M. (1996). The Diversity of Objections to Inequality. In Scanlon, Thomas. The Lindley Lecture. Lawrence: The University of Kansas: 1-18.

Scanlon, T. M. (1998). What we owe to each other. Cambridge, Massachusetts: Belknap Press of Harvard University Press.

Scanlon, T. M. (2018). Why Does Inequality Matter? Oxford University Press.

Stice, E., Spoor, S., Bohon, C., \& Small, D. M. (2008). Relation between obesity and blunted striatal response to food is moderated by Taq1A A1 allele.Science, 322(5900): 449-452.

Volkow, Nora D., \& Wise, Roy A. (2005). How can drug addiction help us understand obesity?. Nature neuroscience, 8(5): 555.

Wallace, R. Jay (1999). Addiction as defect of the will: some philosophical reflections. Law and Philosophy 18: 621-654.

Wang, Gene-Jack, Volkow, Nora D., Thanos, Panayotis K., \& Fowler, Joanna S. (2004). Similarity between obesity and drug addiction as assessed by neurofunctional imaging: A concept review. Journal of Addictive Diseases, 23(3): 39-53.

Whitesell, Mackenzie, Bachand, Annette, Peel, Jennifer \& Brown, Mark (2013). Familial, social, and individual factors contributing to risk for adolescent substance use. Journal of Addiction, Article ID 579310, 9 pages. 